\title{
Analysis of the microtensile bond strength to enamel of two adhesive systems polymerized by halogen light or LED
}

\section{Análise da microtração em esmalte de dois sistemas adesivos ativados por LED ou por luz halógena}

\author{
Ana Paula Morales Cobra Carvalho* \\ Míriam Lacalle Turbino**
}

\begin{abstract}
With the development of composite resin polymerization techniques, LEDs were introduced to the market place. Based on the studied literature, the aim of this study was to evaluate, through microtensile testing, the bond strength to enamel of a composite resin associated to a conventional (multi-bottle) adhesive system or to a self etching primer adhesive system, polymerized by halogen light or LED (light emitting diode). Bovine teeth were divided into 4 groups with 10 teeth each $(n=10)$. Then the adhesives Scotchbond Multipurpose Plus (3M-ESPE) and Clearfil SE Bond (Kuraray) were applied following the manufacturers' instructions. Both systems were polymerized for $10 \mathrm{~s}$ by halogen light (Degulux Soft Start - Degussa Hulls) set at $550 \mathrm{~mW} / \mathrm{cm}^{2}$ or by LED (Kerr Demetron) set at $600 \mathrm{~mW} / \mathrm{cm}^{2}$. The composite resin Filtek Z-250 was applied in four $1 \mathrm{~mm}$ increments with the aid of a square, condensation silicon, $5 \mathrm{~mm}$ x $5 \mathrm{~mm}$ matrix, and polymerized by either of light sources for $40 \mathrm{~s}$. Scotchbond Multipurpose Plus polymerized by halogen light presented the highest bond strength values (39.69 $\pm 7.07 \mathrm{MPa})$, and the other groups did not present statistically significant differences: Scotchbond Multipurpose Plus polymerized by LED $(22.28 \pm 2.63 \mathrm{MPa})$, Clearfil SE Bond polymerized by halogen light $(27.82 \pm 2.65 \mathrm{MPa})$ and by LED $(22.89 \pm 5.09 \mathrm{MPa})$.
\end{abstract}

DESCRIPTORS: Adhesives; Dental bonding; Polymerization; Light-emitting diode (LED).

\begin{abstract}
RESUMO: Com a grande busca pelo desenvolvimento das técnicas de polimerização das resinas compostas e dos sistemas adesivos, foram introduzidos no mercado os LEDs. Com base na literatura estudada, neste trabalho é avaliada a força de união da resina composta ao esmalte associado a um sistema adesivo convencional e a um sistema autocondicionante polimerizados por luz halógena e LED, por meio do teste de microtração. Os dentes bovinos foram divididos em 4 grupos com 10 dentes em cada um (n = 10), para aplicação do adesivo Scotchbond Multipurpose Plus (3M-ESPE) e do Clearfil SE Bond (Kuraray) conforme orientação do fabricante, ambos polimerizados por $10 \mathrm{~s}$ tanto pela luz halógena (Degulux Soft Start - Degussa Hulls) com potência de $550 \mathrm{~mW} / \mathrm{cm}^{2}$ como pelo LED (Kerr Demetron) com potência de $600 \mathrm{~mW} / \mathrm{cm}^{2}$. A resina composta Filtek Z-250 foi aplicada em 4 incrementos de $1 \mathrm{~mm}$ com auxílio de uma matriz de silicona de condensação de formato quadrado com dimensões de $5 \mathrm{~mm} \times 5 \mathrm{~mm}$; sendo polimerizada tanto pela luz halógena como pelo LED por $40 \mathrm{~s}$. O adesivo Scotchbond Multipurpose Plus polimerizado com luz halógena apresentou os maiores valores de adesão $(39,69 \pm 7,07 \mathrm{MPa})$ e os outros grupos não apresentaram diferença estatisticamente significante entre si: Scotchbond Multipurpose Plus polimerizado por LED $(22,28 \pm 2,63 \mathrm{MPa})$, Clearfil SE Bond polimerizado por luz halógena $(27,82 \pm 2,65 \mathrm{MPa})$ e por LED $(22,89 \pm 5,09 \mathrm{MPa})$.

DESCRITORES: Adesivos; Colagem dentária; Polimerização; Light-emitting diode (LED).
\end{abstract}

\section{INTRODUCTION}

Dentistry is developing with the purpose of contributing to a better clinical performance of dental materials. New technologies have been introduced, and among them is the light emitting diode technology (LED). LEDs use gallium nitride semiconductors and, when subjected to an electric current, they produce blue light.
This polymerization system emits a light with a wavelength between 450 and $490 \mathrm{~nm}$, with a peak of $470 \mathrm{~nm}^{15}$, which activates the camphoroquinone. The photo-initiator phenyl propadione (PPD) has an absorption peak of $420 \mathrm{~nm}^{18}$, which means that LEDs are not able to start polymerization of composite resins and adhesive systems that

\footnotetext{
*DDS, Graduate Student; **PhD, Associate Professor - Department of Restorative Dentistry, School of Dentistry, University of São Paulo.
} 
Carvalho APMC, Turbino ML. Analysis of the microtensile bond strength to enamel of two adhesive systems polymerized by halogen light or LED. Braz Oral Res 2005;19(4):307-11.

contain this photo-initiator.

LEDs have some advantages over halogen light: because of the smaller energy necessity, they promote little heat ${ }^{14}$ and have a longer lifetime ${ }^{3}$. In addition, fans are not needed to cool the curing unit $^{3}$.

A study suggested that LEDs should be applied for enough time to promote composite resin monomer conversion ${ }^{5}$. Some studies have related a worse performance of LEDs when compared to that of halogen light ${ }^{1,12,14}$.

Therefore there is the necessity of more studies to evaluate LEDs' performance. Furthermore, it is not certain that LEDs are really efficient when used for the polymerization of adhesive systems, and of darker or microfilled composite resins.

Another aspect to be considered is the efficacy of the bond strength to enamel of self-etching primers. Self-etching primers represent a new concept in adhesion because the acidic primer promotes simultaneously surface etching and its penetration into enamel or dentin. Recently, the effect of self-etching primers on enamel has been studied more frequently because it produces an etch pattern different from that obtained with multi-bottle adhesives. It was observed that the etching pattern of self-etching primers had a smaller quantity of microporosities ${ }^{8}$. A lower degree of acid etching was also observed ${ }^{25}$, although satisfactory bond strength was obtained ${ }^{27}$.

In spite of the multiple steps required by multi-bottle adhesive systems, they are considered effective. Multi-bottle adhesive systems (Scotchbond Multipurpose Plus) have presented greater bond strengths ${ }^{2}$. This result is due to good monomer impregnation in dentin and enamel, 2 to $4 \mu \mathrm{m}$ of hybrid layer, and a uniform adhesive layer $(30 \mu \mathrm{m})^{2}$.

Based on a review of the literature, the aim of this study was to evaluate LED efficacy on the polymerization of different adhesive systems and also to compare the bond strength to bovine enamel of a multi-bottle adhesive system (Scotchbond Multipurpose Plus) and that of a self-etching primer (Clearfil SE Bond).

\section{MATERIAL AND METHODS}

Forty freshly extracted Bovine teeth were separated from their root portions to be used in this study, as some authors have confirmed their applicability as a substitute for human enamel for adhesion testing ${ }^{17}$. After that, their buccal surfaces were ground in a water-cooled mechanical grinder (Politriz-Buehler, Boston, MA, USA), using a 600 grit $\mathrm{Al}_{2} \mathrm{O}_{3}$ abrasive paper to obtain flat, standardized enamel surfaces. The teeth were then stored in distilled water.

The teeth were divided into 4 groups with 10 teeth each $(\mathrm{n}=10)$ as follows:

- Group 1 - Scotchbond Multipurpose Plus (3M ESPE, St. Paul, MN, USA), polymerized by halogen light.

- Group 2 - Scotchbond Multipurpose Plus, polymerized by LED.

- Group 3 - Self-etching primer Clearfil SE Bond (Kuraray Co., Osaka, Japan), polymerized by halogen light.

- Group 4 - Self-etching primer Clearfil SE Bond, polymerized by LED.

The adhesive systems were applied following the manufacturers' instructions and were lightcured for 10 seconds with a light curing unit (Degulux Soft Start, Degussa Hills, Hanau, Germany) set at $550 \mathrm{~mW} / \mathrm{cm}^{2}$, or with a LED unit (Kerr Demetron, Danburry, CT, USA) set at $600 \mathrm{~mW} / \mathrm{cm}^{2}$. After that, the Filtek Z-250 (3M ESPE, St. Paul, MN, USA) composite resin was inserted in 4 increments of $1 \mathrm{~mm}$ each and light-cured for 40 seconds. A silicon-based impression material (Optosil, Heraeus Kulzer GmbH \& Co., KG, Germany) was used as a matrix with dimensions of $5 \mathrm{~mm} \times 5 \mathrm{~mm}$.

The choice of microtensile bond testing was based on studies confirming that higher bond strength values are obtained in smaller areas $^{22,23}$.

In order to obtain the specimens, the teeth were mounted on an acrylic resin base. Composite resin and tooth structure were cut with a diamond disc in the cervico-occlusal and mesiodistal directions. The specimens thus prepared had a rectangular cross-sectional area of approximately $1 \mathrm{~mm}^{2}{ }^{4}$ For cutting, the Lab Cut 1010 (Extec corp. - Enfield, CT, USA) machine was used with a diamond disc (Extec corp. - Enfield, CT, USA), set at $250 \mathrm{rpm}$ of speed for the mesiodistal direction and at $125 \mathrm{rpm}$ for the cervico-occlusal direction. Only the 4 central specimens of each tooth were used for the microtensile bond testing.

The composite resin increments were inserted so as to maintain the proportion between the lengths of tooth structure and composite resin. A pattern was thus created to avoid any influence that could be caused by different dimensions of the 2 extremities during the stress applied in the microtensile test.

The specimens were then fixed at either side with cyanoacrylate adhesive (Super Bonder Gel, 
Carvalho APMC, Turbino ML. Analysis of the microtensile bond strength to enamel of two adhesive systems polymerized by halogen light or LED. Braz Oral Res 2005;19(4):307-11.

Loctite, São Paulo, SP, Brazil) in the Geraldeli device $^{21}$, which was used for the microtensile bond test. Hence, the area of adhesion was placed perpendicular to the direction of the applied stress. The specimen device was mounted in the universal testing machine Mini Instron model 4442 (Instron Canton, CT, USA) set at a speed of $0.5 \mathrm{~mm} / \mathrm{min}$.

Three types of fracture were obtained: in the adhesive junction, in the enamel area and in the composite resin area; mixed fractures were also observed. However, only the fractures in the adhesive junction were measured with a caliper and, after that, the bond strength values were transformed to MPa. Using this methodology, the bond strength values were obtained according to the cross-sectional specimen areas. The values were submitted to statistical analysis of variance (ANOVA) and to Tukey's test.

The original results consist of 160 bond strength values (in $\mathrm{MPa}$ ) related to 40 teeth, with 4 specimens per tooth. Furthermore, only specimens with adhesive fracture were used for the statistics. An average of these values was then calculated, resulting in 40 values, 10 for each group.

\section{RESULTS}

The values submitted to statistical analysis of variance (ANOVA) presented statistical significance for 2 factors: source $(\mathrm{F}=55.55)$ and adhesive $(F=14.12)$, and for the relation source versus adhesive $(F=17.35)$. With the relation averages,

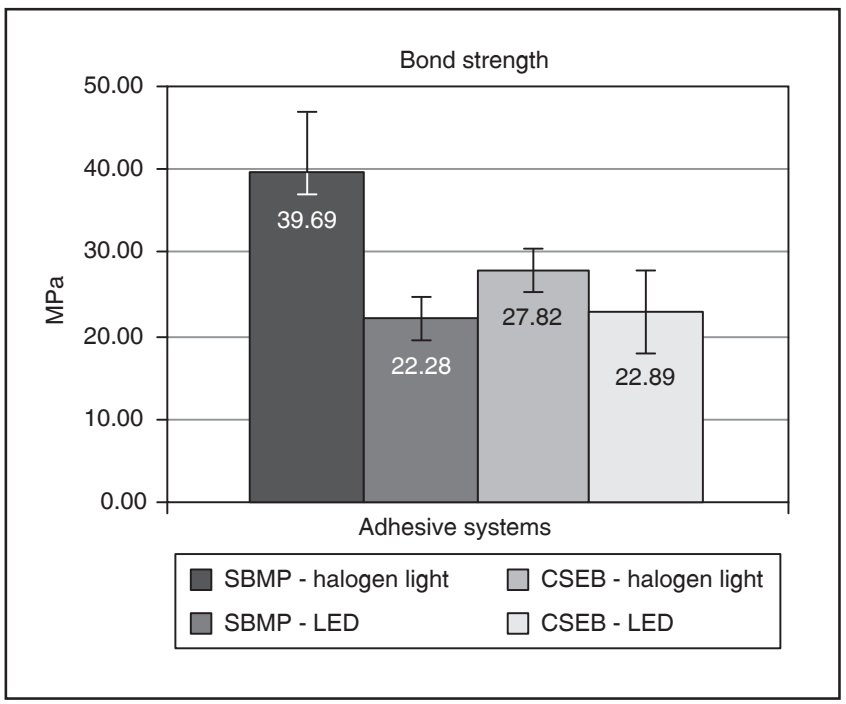

GRAPH 1 - Microtensile bond strength to enamel values of two adhesive systems polymerized by halogen light and LED.
Tukey's test was done at the $5 \%$ level of significance. Scotchbond Multipurpose Plus polymerized with halogen light presented higher bond strength values and there was no statistically significant difference between the other groups.

The averages and standard deviations for the 4 groups are presented in Graph 1 and Table 1 .

\section{DISCUSSION}

In literature, some differences between polymerization with halogen light and with LED are reported.

In a comparison of LED versus halogen light and another source of polymerization, it was concluded that it is necessary to consider curing unit power, LED number and exposure time. Only powerful LEDs can be compared to halogen light ${ }^{1}$.

Some studies have described LED results versus halogen light results. The composite resin polymerization depth of a curing unit with 27 LEDs set at $350 \mathrm{~mW} / \mathrm{cm}^{2}$ was $20 \%$ smaller than that of halogen light ${ }^{12}$. Exposure time needed by LEDs for an adequate composite resin polymerization was longer than that required by halogen light ${ }^{14}$. The composite resin mechanical properties obtained after polymerization with LEDs set at $300 \mathrm{~mW} /$ $\mathrm{cm}^{2}$ were inferior or similar to those obtained with halogen light, however the LED results fulfilled the requirements set by the International Standards Organization (ISO) ${ }^{1}$. The poorer performance (inferior mechanical properties) of LEDs can be explained by the use of a unit with 7 LEDs with only $150 \mathrm{~mW} / \mathrm{cm}^{2} .{ }^{7}$ A curing unit with 61 LEDs promoted a greater depth of polymerization of composite resins than that of halogen light ${ }^{9}$.

In another study, only the Elipar FreeLight LED (3M-ESPE) set at $400 \mathrm{~mW} / \mathrm{cm}^{2}$ achieved adequate polymerization of superficial and deeper layers of composite resin specimens ${ }^{26}$. This means that this LED promoted the same hardness val-

TABLE 1 - Microtensile bond strength to enamel values of two adhesive systems polymerized by halogen light and LED.

\begin{tabular}{l|c}
\hline \multicolumn{1}{c|}{ Groups } & Mean \pm sd \\
\hline SBMP-halogen light & $39.69 \pm 7.07 \mathrm{MPa}$ \\
\hline SBMP-LED & $22.28 \pm 2.63 \mathrm{MPa}$ \\
\hline CSEB-halogen light & $27.82 \pm 2.65 \mathrm{MPa}$ \\
\hline CSEB - LED & $22.89 \pm 5.09 \mathrm{MPa}$ \\
\hline \hline
\end{tabular}

SBMP: Scotchbond Multipurpose Plus. CSEB: Clearfil SE Bond. 
Carvalho APMC, Turbino ML. Analysis of the microtensile bond strength to enamel of two adhesive systems polymerized by halogen light or LED. Braz Oral Res 2005;19(4):307-11.

ues as those of halogen light ${ }^{26}$. The hardness values - and, therefore, the effectiveness of composite resin polymerization - obtained with the GC e-light LED (GC), set at $600 \mathrm{~mW} / \mathrm{cm}^{2}$ were lower than those produced by halogen light at $800 \mathrm{~mW} / \mathrm{cm}^{2}{ }^{26}$ Therefore, effectiveness of LED curing lights depends on the kind of curing unit used ${ }^{26}$.

It was also observed that only a more powerful LED unit $\left(320 \mathrm{~mW} / \mathrm{cm}^{2}\right)$ obtained hardness values of the Filtek $Z-250$ composite resin similar to those of halogen light $\left(800 \mathrm{~mW} / \mathrm{cm}^{2}\right)^{11}$. A less powerful LED unit $\left(160 \mathrm{~mW} / \mathrm{cm}^{2}\right)$ used in the same study needed more exposure time to obtain results similar to those of halogen light ${ }^{11}$.

When comparing a LED unit at $300 \mathrm{~mW} / \mathrm{cm}^{2}$ to a conventional light set at $455 \mathrm{~mW} / \mathrm{cm}^{2}$, one study related that the depths of polymerization of flowable, microfill and hybrid composite resins obtained with LED were greater than those obtained with halogen light ${ }^{15}$.

A LED curing unit with $64 \%$ of halogen light irradiation produced a satisfactory depth of polymerization of composite resins ${ }^{15}$. Moreover, LED can be useful in clinical practice because its performance is not significantly reduced with the reduction of exposure time, contrasting with the behavior of halogen light ${ }^{15}$.

All these studies permitted to conclude that the use of reliable and powerful LED light-curing units is advisable in order to produce effective polymerization and bond strength results similar to those of halogen light.

Some studies have correlated depth of polymerization and monomer degree of conversion ${ }^{12,15}$. An adequate polymerization of adhesive systems and composite resins is a guarantee of good clinical results. Moreover, higher molecular weight monomers as Bis-GMA or urethane dimethacrylate (UDMA) always have residual non-reacting $\mathrm{C}=\mathrm{C}$, mainly because of limitations in the mobility of reactive groups caused by the rapid formation of a cross-linked polymeric network ${ }^{6}$. Hence, a powerful and effective light-curing unit is necessary for an adequate polymerization.

Based on the related literature, it can be assumed that the inferior performance of the LED curing unit (LED Kerr Demetron) used in this study to polymerize the Scotchbond Multipurpose Plus adhesive can be explained because this LED unit promoted a lower degree of polymerization when compared to the halogen light Degulux. Therefore, the Kerr Demetron LED unit set at $600 \mathrm{~mW} / \mathrm{cm}^{2}$, when applied for $10 \mathrm{~s}$, is not equivalent to the Degulux Soft Start halogen light unit set at $550 \mathrm{~mW}$ / $\mathrm{cm}^{2}$ applied for the same $10 \mathrm{~s}$. It is advisable to use the LED curing unit used in this study for a longer period of time.

The similar bond strength values obtained in this study when Clearfil SE Bond was polymerized with halogen and with LED can be explained by the unreliable performance of this adhesive in enamel. The length of resin tags originated from self etching primers has been shown to contribute little to the bond strength of resin to enamel, and bonding is mainly attributable to the ability of resin in penetrating between the enamel crystallites and $\operatorname{rods}^{13}$.

The acidic primer promotes a selective dissolution of enamel prisms, creating micro-porosities for resin penetration ${ }^{16}$. Some studies have related that self-etching primers present bond strengths lower than or similar to those presented by one-bottle adhesive systems with acid etching ${ }^{16}$. This can be explained because the resin fails to penetrate deeply into enamel prisms ${ }^{16}$. As a consequence, the adhesion between enamel and resin fails after some time in function in the mouth ${ }^{16}$.

It was observed that self-etching primers did not create a deep etch pattern, differently from the phosphoric acid application only ${ }^{20}$. Empty areas in the hybridized enamel region in the enamel/ resin interface were also observed ${ }^{19}$. The balance between demineralization depth and extension of monomer penetration of the self-etching primers is the key to a good quality adhesion between enamel and resin $^{23}$.

Self-etching primers had limited demineralization and impregnation depths because of wet dentin and ionic effects of high calcium and phosphate concentrations, which limited the apatite crystals dissolution ${ }^{28}$. Due to the high enamel mineral content, this effect should be considered when selfetching primers are applied in enamel.

Even though the self-etching primers do not have the same performance as that of conventional systems, they present high bond strength values and good clinical outcomes ${ }^{10,24}$. Despite these opinions, the self-etching primers were not better than the conventional systems when applied to dentin ${ }^{17}$. Hence, the application of conventional adhesive systems to enamel and dentin is considered a safer alternative.

\section{CONCLUSION}

1. Considering the Scotchbond Multipurpose Plus multi-bottle adhesive system, the polymerization with halogen light resulted in higher 
Carvalho APMC, Turbino ML. Analysis of the microtensile bond strength to enamel of two adhesive systems polymerized by halogen light or LED. Braz Oral Res 2005;19(4):307-11.

bond strength values than those obtained with polymerization with LED.

2. Considering the Clearfil SE Bond self-etching primer, there were no statistically significant differences between polymerization with halogen light or with LED.

3. There were no statistically significant differences between the Scotchbond Multipurpose

\section{REFERENCES}

1. Asmussen E, Peutzfeldt A. Light-emitting diode curing: Influence on selected properties of resin composites. Quintessence Int 2003;34:71-5.

2. Bouillaguet S, Gysi P, Wataha JC, Ciucchi B, Cattani M, Godin $\mathrm{C}$ et al. Bond strength of composite to dentine using conventional, one-step, and self-etching systems. J Dent 2001;29(1):55-61.

3. Burgess JO, Walker RS, Porche CJ, Rappold AJ. Light curing - an update. Compend Contin Educ Dent 2002;23(10):889-92,894,896.

4. Cardoso PEC, Plácido E, Francci CE. Microleakage of Class V resin based composite restorations using five simplified adhesive systems. Am J Dent 1999;12:291-4.

5. Caughman WF, Rueggeberg FA. Shedding new light on composite polymerization. Oper Dent 2002;27:636-8.

6 . Chung KH. The relationship between composition and properties of posterior resin composites. J Dent Res 1989;69:852.

7. Dunn WJ, Bush AC. A comparison of polymerization by light emitting diode and halogen based light curing units. J Am Dent Assoc 2003;133(3):335-41.

8. Ferrari M, Mannocci F, Liner AV, Davidson CL. Effect of two etching times on the sealing ability of Clearfil Bond 2 in class V restorations. Am J Dent 1997;10:66-70.

9. Fujibayashi K, Ishimaru K, Takhashi N, Kohno A. Newly developed curing unit using blue light emitting diodes. Dent Jpn 1998;34:49-53.

10. Hannig M, Reinhardt KJ, Bott B. Self etching primer vs phosphoric acid: an alternative concept for compositeto-enamel bonding. Oper Dent 1999;24(3):172-80.

11. Hofmann N, Hugo B, Klaiber B. Effect of irradiation type (LED or QTH) on photo-activated composite shrinkage strain kinetics, temperature rise and hardness. Eur J Oral Sci 2002;110:471-9.

12. Jandt KD, Mills RW, Blackwell GB, Ashworth SH. Depth of cure and compressive strength of dental composites cured with blue light emitting diodes (LEDs). Dent Mater 2000;16:41-7.

13. Kanemura N, Sano H, Tagami J. Tensile bond strength to and SEM evaluation of ground and intact enamel surfaces. J Dent 1999;27(7):523-30.

14. Leonard DL, Charlton DG, Roberts HW, Cohen ME. Polymerization efficiency of LED curing lights. J Esthet Restor Dent 2002;14:286-95.
Plus adhesive polymerized with LED and the Clearfil SE Bond adhesive polymerized with halogen light or with LED.

4. The multi-bottle adhesive system presented higher bond strength values than the selfetching primer.

15. Mills RW, Jandt KD, Ashworth SH. Dental composite depth of cure with halogen blue light emitting diode technology. Br Dent J 1999;186(8):388-91.

16. Miyazaki M, Sato M, Onose H, Moore BK. Influence of thermal cycling on dentin bond strength of two step bonding systems. Am J Dent 1998;11:118-22.

17. Nakamichi I, Iwaku M, Fusayama T. Bovine teeth as possible substitutes in the adhesion test. J Dent Res 1983;62:1076-81.

18. Park YJ, Chae KH, Rawls HR. Development of a new photoinitiation system for dental light-cure composite resins. Dent Mater 1999;15(2):120-7.

19. Perdigão J, Francci C, Swift EJ, Ambrose WW, Lopes M. Ultra-morphological study of interaction of adhesives with carbamide peroxide-bleached enamel. Am J Dent 1998;11:291-301.

20. Perdigão J, Lopes L, Lambrechts P, Leitão J, van Meerbeek B, Vanherle G. Effect of a self-etching primer on enamel shear bond strengths and SEM morphology. Am J Dent 1997;10:141-6.

21. Perdigão JE. In vivo influence of residual moisture on microtensile bond strength of one-bottle adhesives. J Esthet Restor Dent 2002;14(1):31-8.

22. Phrukkanon S, Burrow MF, Tyas MJ. The influence of cross sectional shape and surface area on the microtensile bond test. Dent Mater 1998;14:212-21.

23. Sano H, Takatsu T, Ciucci B, Horner JA, Matthews WG, Pashley DH. Nanoleakage: Leakage within the hybrid layer. Oper Dent 1994;20:18-25.

24. Shimada Y, Senawongse P, Harnirattisai C, Burrow MF, Nakaoki Y, Tagami J. Bond strength of two adhesive systems to primary and permanent enamel. Oper Dent 2002;27:403-9.

25. Shono T. Pulpal responses to light-cured restorative glass polyalkenoate cements, and ultrastructure of cementdentin interface. Japan J Conserv Dent 1995;38:514-48.

26. Soh MS, Yap AUJ, Siow KS. Effectiveness of composite cure associated with different curing modes of LED lights. Oper Dent 2003;28(4)371-7.

27. Watanabe I. Photocure bonding agents to ground dentin. Jpn J Dent Mater 1992;11:955-73.

28. Yoshiyama M, Carvalho R, Sano H. Regional bond strength of resins to human root dentine. J Dent Res 1996;24:435-42. 